\title{
recillunds
}

Revista Científica Mundo de la Investigación y el Conocimiento

Esther Mónica Jara Fernández ${ }^{\text {a }}$; Francisco Luis León Chérrez ${ }^{\text {b }}$ Gabriel Yovany Suqui Romero ${ }^{\mathrm{c}}$

La teoría de la imputación en la discusión doctrinaria actual. Especial referencia al Código Orgánico Integral Penal

The theory of imputation in the current doctrinal discussion. Special reference to the Organic Comprehensive Criminal Code

Revista Científica Mundo de la Investigación y el Conocimiento. Vol. 3 núm.3, septiembre, ISSN: 2588-073X, 2019, pp. 1198-1222

DOI: $10.26820 /$ recimundo/3.(3).septiembre.2019.1198-1222

URL: http://recimundo.com/index.php/es/article/view/566

Código UNESCO: 5605 Legislación y Leyes Nacionales

Tipo de Investigación: Artículo de Revisión

Editorial Saberes del Conocimiento

Recibido: 15/05/2019

Aceptado: 23/06/2019

Publicado: 30/09/2019

Correspondencia: monicajara27@ outlook.com

a. Estudiante de la Universidad Técnica de Machala; Machala, Ecuador; monicajara27@ outlook.com

b. Estudiante de la Universidad Técnica de Machala; Machala, Ecuador; franciscoleon00@ gmail.com

c. Doctor en Jurisprudencia y Abogado de los Tribunales de Justicia de la República; Máster Universitario en Derecho, Orientación Investigadora Especialidad en Derecho Penal; Docente Universidad Técnica de Machala; Machala, Ecuador; gsuqui@utmachala.edu.ec 


\section{La teoría de la imputación en la discusión doctrinaria actual. Especial referencia al Código Orgánico Integral Penal}

Vol. 3, núm. 3., (2019)

Esther Mónica Jara Fernández; Francisco Luis León Chérrez; Gabriel Yovany

Suqui Romero

\section{RESUMEN}

Conforme ha ido avanzando la sociedad de riesgo, ha necesitado en materia de Derecho penal de teorías que recojan constructos modernos de cara a afrontar de manera también moderna y oportuna, las relaciones sociales cambiantes. En ese escenario las corrientes finalistas y funcionalistas son las que en la actualidad monopolizan el pensamiento penal en los distintos ordenamientos jurídicos de la región. Por su parte, el Derecho Penal y Procesal Penal ecuatoriano recogido en el Código Orgánico Integral Penal, recogen en conjunción, las diferentes teorías del Derecho Penal y Procesal. El primero de ellos, se ha ido alejando de la delimitación clásica y causal de los tipos penales, que históricamente se limitaba a la determinación de la presencia o ausencia de una causa y un efecto, para dar lugar a un sistema que evalúa múltiples aristas de la acción, la omisión y las acciones u omisiones en las que incurre la víctima, entre otras características presentes en el escenario moderno de la acción. El presente trabajo tiene como objetivo analizar el estado de la cuestión de la regulación dogmática que respecto de la teoría de la imputación desarrolla el COIP. Con el auxilio de métodos exegéticos, sistemáticos, comparativos y analíticos se arribó a la conclusión que el COIP permite la aplicación indistinta de postulados tanto del finalismo cuanto del funcionalismo.

Palabras Claves: Finalismo; Funcionalismo; Tipicidad; Imputación objetiva. 


\title{
La teoría de la imputación en la discusión doctrinaria actual. Especial referencia al Código Orgánico Integral Penal
}

Vol. 3, núm. 3., (2019)

Esther Mónica Jara Fernández; Francisco Luis León Chérrez; Gabriel Yovany

Suqui Romero

\begin{abstract}
As the risk society has progressed, it has needed in the matter of criminal law theories that collect modern constructs in order to deal with changing and modern social relations in a modern and timely manner. In this scenario, the finalist and functionalist currents are those that currently monopolize criminal thinking in the different legal systems of the region. On the other hand, the Ecuadorian Criminal and Criminal Procedure Law included in the Integral Criminal Organic Code, collectively, collect the different theories of Criminal and Procedural Law. The first one, has moved away from the classical and causal delimitation of criminal types, which historically was limited to the determination of the presence or absence of a cause and an effect, to give rise to a system that evaluates multiple edges of the action, omission and actions or omissions incurred by the victim, among other features present in the modern scenario of the action. This paper aims to analyze the status of the dogmatic regulation issue that COIP develops regarding the imputation theory. With the help of exegetical, systematic, comparative and analytical methods, it was concluded that COIP allows the indistinct application of postulates of both finalism and functionalism.
\end{abstract}

Key Words: Finalism; Functionalism; Typicality; Objective imputation. 


\section{La teoría de la imputación en la discusión doctrinaria actual. Especial referencia al Código Orgánico Integral Penal}

Vol. 3, núm. 3., (2019)

Esther Mónica Jara Fernández; Francisco Luis León Chérrez; Gabriel Yovany

Suqui Romero

\section{Introducción.}

Los riesgos continuos a los que están expuestos los habitantes de una sociedad, no pueden ni debe pasar desapercibidos por el Derecho penal en la meda que aquellos involucren conductas penalmente relevantes. Sin embargo, el carácter coercitivo de esta rama del Derecho, podría también en ocasiones generar serios cuestionamientos a su intervención en la sociedad, sobre todo cuando su aplicación sea defectuosa producida, entre otras cosas, por ejemplo, cuando la naturaleza del mundo de lo fáctico presente situaciones controvertibles muy debatibles que merezcan razonamientos jurídicos acorde a los actuales paradigmas sociales. De ahí que, sea necesario su abordaje a la luz no solamente de su estricta literalidad regulatoria, sino también de un profundo análisis dogmático de sus fundamentos punitivos.

La teoría del delito, entendida como el sistema dogmático que permite categorizar las conductas con el fin de verificar su relevancia penal, tiene como propósito la verificación de sí las acciones u omisiones ejercidas por los individuos son adecuadas para ejercitar el ius puniendi estatal. En esa revisión de las conductas actúa la teoría del delito como <<administrador >> de la última ratio del Derecho Penal, brindando como garantía a los individuos un completo análisis penal de su posible conducta delictual, estableciendo además, numerosas causas de exclusión que coadyuvan a una interpretación integral de la acción, controlando si las características de la conducta imputada atraviesa estos filtros propuestos.

Respecto del Código Orgánico Integral Penal (COIP) de 2014, se puede asumir que no es un instrumento legal fatalmente predeterminado a una corriente del pensamiento penal, en tal virtud, no se enmarca solamente en los postulados de una corriente del delito, sino que de su 


\section{La teoría de la imputación en la discusión doctrinaria actual. Especial referencia al Código Orgánico Integral Penal}

Vol. 3, núm. 3., (2019)

Esther Mónica Jara Fernández; Francisco Luis León Chérrez; Gabriel Yovany

Suqui Romero

lectura permite teorizar y matizar cuestiones que bien pueden encasillarse en una u otra corriente doctrinal (finalismo, funcionalismo, por ejemplo).

En este trabajo se abordan temas puntuales de teoría del delito a la luz de las corrientes clásicas del pensamiento penal, priorizando su análisis al concreto caso ecuatoriano, es decir a la regulación del COIP.

\section{I.1. Antecedentes y generalidades.}

\section{I.1.1 El Código Penal.}

Desde la independencia del Ecuador hasta la actualidad, la normativa penal ha ido transformándose de manera continua, ligada en mayor o menor medida a los propósitos gubernamentalistas de turno y a las necesidades político-criminales de seguridad en la población. En 1837 Ecuador desarrolla su primer esbozo de Código Penal, que "no representa mayor novedad, debido precisamente, al hecho innegable de que faltaba gente preparada para legislar con propiedad" (Vaca, 2014, pág. 111). De esta manera, el Ecuador ha ido superando distintas adversidades jurídico-sociales en su carrera por crear un Código Penal óptimo. Cabe hacer mención que durante largos lapsos de tiempo, en materia penal, la legislación se bifurcó en dos cuerpos normativos, teniendo por un lado un Código Penal que recogía la parte especial así como lo referente a los principios rectores del Derecho Penal y por otra parte un Código de procedimiento penal que en su redacción contenía los aspectos procesales.

Dadas estas aclaraciones, como antecedente directo del COIP texto penal vigente, se encontraba en funcionamiento el Código Penal de 1971 (a partir de ahora CP), con su respectivo 


\section{La teoría de la imputación en la discusión doctrinaria actual. Especial referencia al Código Orgánico Integral Penal}

Vol. 3, núm. 3., (2019)

Esther Mónica Jara Fernández; Francisco Luis León Chérrez; Gabriel Yovany

Suqui Romero

Código de Procedimiento Penal. Este CP no fue la excepción, y como sus antecesores, tuvo incontables reformas que se suscitaron por los constantes cambios socio-políticos que sufrió el país con la dictadura militar y el regreso a la democracia.

Observando el CP desde el punto de vista materia del presente trabajo, este cuerpo normativo era estrictamente causalista al establecer en su artículo 3 que "Se presume de derecho que las leyes penales son conocidas de todos aquellos sobre quienes imperan. Por consiguiente, nadie puede invocar su ignorancia como causa de disculpa", de ahí se colige que no permitía "ahondar en la culpabilidad, es decir, brindar un tratamiento subjetivo del agente sobre la falta de conciencia de la antijuridicidad de la norma penal” (Velepucha Ríos, 2018).

\section{I.1.2 Anteproyecto y Proyecto de Código Orgánico Integral Penal.}

El COIP tuvo un total de 2 debates compuestos de 15 sesiones y un veto presidencial. En estos debates se descartó la inclusión del error de tipo, y con el veto presidencial, lo mismo se hizo con el error de prohibición. Esta exclusión, tal como recoge García Falconí, careció de justificación legal pertinente, ya que "las explicaciones fueron de todos los colores y todos los matices, pero en el fondo lo que resultó evidente es la supina ignorancia en el tema por parte de los actores legislativos y de gobierno" (2014). Por su parte, Zambrano Pasquel indica que si bien se suprimió el art. 35 del COIP, referente al error de prohibición (error que destaca como el producto del desconocimiento y mala asesoría), "no se han vetado los artículos 34 y 36 del COIP, por lo que sostenemos que el error de prohibición se mantiene vigente en el COIP” (2017, pág. 219). 


\section{La teoría de la imputación en la discusión doctrinaria actual. Especial referencia al Código Orgánico Integral Penal}

Vol. 3, núm. 3., (2019)

Esther Mónica Jara Fernández; Francisco Luis León Chérrez; Gabriel Yovany

Suqui Romero

La teoría del error en el ordenamiento jurídico reportaba de imperativa y vital importancia ser anexada al conjunto de teorías que de manera expresa o tácita son recogidas actualmente por el COIP. Sin embargo, esta necesidad no se vio reflejada en el vigente cuerpo normativo, lo que provocó reacciones entre los juristas y doctrinarios locales, y es que los miembros del gobierno y de la Asamblea no concibieron que "la norma jurídico penal no tiene una función de mero control social (...) o, aún peor, de pura dominación o represión” (Luzón Peña, 2016, pág. 76). Y es que, este acto de exclusión del error de tipo y el error de prohibición, a entender de García Falconí más que evitar los supuestos manejados por los actores llamados al diseño del COIP del riesgo de "aplicarse pena sin culpabilidad o asumir por parte de las propias instancias oficiales que los jueces no están preparados para implementar figuras" (2014), lo que según el mismos autor, coloca “a los operadores de justicia en un limbo que, ese sí, va a dar lugar a una aplicación arbitraria de estas figuras" (2014), dejando pasar la oportunidad de dar "un gran paso de la normativa penal en vigencia en la nación hacia un derecho evolucionado" (Moya Molina, 2014, pág. 30).

En fin, pese a que el COIP de manera expresa no regula el error de tipo y el error de prohibición, pero como se observará más adelante, de algún modo se permite el debate en sede de la culpabilidad.

\section{I.1.3 El Causalismo.}

Dentro del curso de la historia del Derecho penal, esta teoría es concebida como clásica y neoclásica, con postulados que en la mayoría de los casos han sido debatidos y reemplazados por teorías más modernas. Dentro de esta teoría, el resultado ocupa una posición capital, ya que, 


\section{La teoría de la imputación en la discusión doctrinaria actual. Especial referencia al Código Orgánico Integral Penal}

Vol. 3, núm. 3., (2019)

Esther Mónica Jara Fernández; Francisco Luis León Chérrez; Gabriel Yovany

Suqui Romero

como expresa Von Liszt, citado por Roxin, la "acción es conducta voluntaria hacia el mundo exterior; más exactamente: modificación, es decir, causación o no-evitación de una modificación (de un resultado) del mundo exterior" (Roxin, 2014, pág. 237).

El causalismo idealiza a la acción "en términos físicos o naturalísticos, integrada por un movimiento corporal y el resultado de una modificación en el mundo exterior, unidos por un nexo causal” (Peña Gonzales \& Almanza Altamirano, 2010, pág. 22). Es por lo tanto, para esta corriente el resultado lo que importa a la hora de determinar si una acción tiene relevancia penal, situación que es criticada en el sentido de que se trata de "una teoría para el análisis de la conducta dentro de todo el sistema de análisis del delito" (Díaz Aranda, 2018, pág. 18), sirviendo únicamente al estudio del primero de los estadios o niveles de la estructura del delito (conducta típica).

En el sentido advertido, se entiende "que es acción todo aquel movimiento corporal voluntario que causa un resultado" (Larrauri Pijoan, 2016, pág. 222), de ahí que, lo que cuenta es la "simple "voluntariedad" del agente que actúa, es decir, existe una provocación de determinados efectos en el mundo exterior a través del querer y que significa una producción causal de esos efectos sin importar si fue o no "querida"" (Gómez Toledo, 2009). Para esta corriente los elementos subjetivos del delito dolo y culpa se ubican en sede de la culpabilidad.

\section{I.1.4.Finalismo}

El concepto de acción en el finalismo es "distinto del de las anteriores concepciones sistemáticas y mucho más rico en contenido" (Roxin, 2014, pág. 199). Esta concepción radica en 


\section{La teoría de la imputación en la discusión doctrinaria actual. Especial referencia al Código Orgánico Integral Penal}

Vol. 3, núm. 3., (2019)

Esther Mónica Jara Fernández; Francisco Luis León Chérrez; Gabriel Yovany

Suqui Romero

la dirección final de la acción, como meta o propósito de la acción humana, entendiéndose por tal, en palabras de Welzel citado por Maurach como "el hombre sobre la base de su saber causal, puede prever, en cierta medida, los posibles efectos de su actividad, proponerse metas de diferente naturaleza, y encausar conforme a un plan su actividad a ésta consecución de la meta" (Maurach, 1994, pág. 206). De esta manera, "mediante su anticipación mental y la correspondiente selección de medios, el hombre controla el curso causal dirigiéndolo hacia un determinado objetivo, es decir, lo supradetermina de modo final” (Roxin, 2014, pág. 199), mostrando por tanto desde el primer momento una intención marcada.

El camino recorrido por el delincuente atraviesa tres fases "comienza con la representación mental de la meta buscada, sigue con la elección de los medios precisos para alcanzarla y termina con la realización de la acción en el mundo del acaecer real" (Gómez Toledo, 2009, pág. 25), pensamiento que apoya lo desarrollado por los finalistas y que deja entrever de manera clara como el ser humano controla el curso causal desde un comienzo. Esta corriente ubica en el análisis de la teoría del delito al dolo y la culpa en sede de la tipicidad.

\section{I.1.5. Funcionalismo}

Esta corriente surge como la unión del Derecho con la Sociología, donde las teorías de funcionalismo absoluto de Malinoswski, funcionalismo relativizado de Merton, sistémico de Luhmann, y estructural de Parsons, coadyuvan con los conceptos de sistemas autopoieticos de Maturana y Varela para desembocar en el funcionalismo penal de Jakobs. 


\section{La teoría de la imputación en la discusión doctrinaria actual. Especial referencia al Código Orgánico Integral Penal}

Vol. 3, núm. 3., (2019)

Esther Mónica Jara Fernández; Francisco Luis León Chérrez; Gabriel Yovany

Suqui Romero

Como principal cambio, esta corriente concibe que las comunicaciones no se realizan únicamente entre la norma y el delincuente, "sino al conjunto de ciudadanos que poseen ciertas expectativas, que la norma expresa (norma jurídico penal = expectativa normativa), mostrándoles que están en lo cierto y que el defecto está en el actuar del otro" (García Amado, 2000, pág. 245). Esto lleva a entender que "tanto el que delinque como el que cumple la norma se comunican con el todo social mediante sus actos, si bien con $<<$ sentido $>>$ distinto" (2000, pág. 245).

\section{I.2.Teoría del Delito}

La teoría del delito es un sistema categorial, clasificatorio y secuencial en el que, de peldaño en peldaño se van elaborando, a partir del concepto básico del Derecho penal, los diferentes elementos esenciales comunes a todas las formas de aparición delictual (Muñoz Conde \& García Arán, Derecho Penal. Parte General, 2004, pág. 205). Esta teoría tiene como fin verificar en una conducta los elementos del delito, de manera que se justifique la respuesta judicial y se habilite el poder punitivo del Estado; ofreciendo un modelo de análisis que facilite la enseñanza del Derecho así como el planteo y decisión de los casos en los tribunales (Zaffaroni, Alagia, \& Slokar, Manual de Derecho penal. Parte General, 2006, págs. 288-289).

Empleada por Von Liszt con fines académicos, permite el análisis secuencial y estructurado del delito de cara a determinar o no la responsabilidad penal de personas sujetas a un proceso o investigación criminal. 


\section{La teoría de la imputación en la discusión doctrinaria actual. Especial referencia al Código Orgánico Integral Penal}

Vol. 3, núm. 3., (2019)

Esther Mónica Jara Fernández; Francisco Luis León Chérrez; Gabriel Yovany

Suqui Romero

\section{I.2.1. La teoría del delito del CP al COIP.}

Como se estableció en puntos anteriores, la acción en el Derecho Penal es una modificación del mundo exterior, ya sea "expresada mediante el movimiento o la inmovilidad" (Iberley, 2013), con independencia de si esta acción es consciente o inconsciente. En el CP estas acciones, llamadas infracciones se subdividían en delitos y contravenciones (art. 10). De igual manera, podían ser cometidas de modo doloso: intencional y preterintencional (art. 13 y 14); y culposo (art. 14). Dentro de este camino que debe recorrer una acción para ser punible, el CP en el art. 13 reflejaba el carácter de adecuación de la conducta a la norma, propio de la tipicidad.

Como causas de exclusión de la culpabilidad, el art. 15 establecía que las infracciones, sean acciones u omisiones, no serían punibles cuando fueran resultado de caso fortuito o fuerza mayor.

Como reflejo de teorías finalistas de funciones, el art. 12 establecía que no impedir un acontecimiento, estando en la obligación jurídica de evitar que suceda, equivalía a cometerlo. Esta figura se ampliaría en el COIP con la omisión dolosa. La tentativa se desarrollaba en el art. 16, mientras que las figuras de la proposición y de la conspiración estaban determinadas en el art. 17.

Si bien los errores no estaban contemplados de manera expresa en el CP, sí existían algunos delitos donde la falta de intención de cometer un acto dañoso estaba contemplada, o como los relacionados con la inviolabilidad del secreto del art. 197 que de forma expresa se refiere a él, estos casos hacían prever su dogmática. El error de prohibición estaba descartado 


\section{La teoría de la imputación en la discusión doctrinaria actual. Especial referencia al Código Orgánico Integral Penal}

Vol. 3, núm. 3., (2019)

Esther Mónica Jara Fernández; Francisco Luis León Chérrez; Gabriel Yovany

Suqui Romero

dado que el art. 3 establecía que no se podía invocar la ignorancia de la norma como causa de disculpa. Ya en el COIP, el Anteproyecto preveía de forma expresa las dos clases de errores, no obstante la voluntad legislativa reformadora, optó por excluirlos.

Por su parte, en cuanto a la conducta, en el COIP se coloca en el primer estadio y se puede presentar como acción u omisión. Para Zambrano Pasquel, la acción es "un mero movimiento corporal causado de una manera determinada por un acto voluntario, pero se entiende por voluntario al que está libre de presión mecánica o psicológica” (2017, pág. 373).

Si bien el COIP no define a la acción propiamente dicha, sí la incluye como una modalidad de la conducta (art. 23) así como la capacidad que tiene la acción de ser una conducta penalmente relevante (art. 22). Para Jescheck \& Wiegend, la finalidad descansa en la capacidad de la persona para prever las consecuencias que se vayan a desprender de su intervención causal, así como la dirección que hace el sujeto activo encaminándose a su objetivo propuesto y con el uso de sus propios medios (García Falconí, 2014, pág. 247).

Luego, el COIP describe cuales son las causas de exclusión de la conducta, encontrando en el artículo 24 la fuerza física irresistible, los movimientos reflejos o los estados de plena inconciencia. Como fuerza física irresistible se puede entender que es "la que reduce al cuerpo a una condición mecánica sea impulsado por fuerza externa o interna” (Zaffaroni, 2007, pág. 326). Por otra parte, los movimientos o actos reflejos son reacciones orgánicas o respuestas musculares desconectadas por completo de la posibilidad de control volitivo (Fernández Carrasquilla, 2011, pág. 290). En cuanto al estado de plena inconciencia, cabe destacar que "son estados en el cual el cuerpo humano presenta una completa inactividad de las funciones de la mente" (Serrano, 2015, 


\section{La teoría de la imputación en la discusión doctrinaria actual. Especial referencia al Código Orgánico Integral Penal}

Vol. 3, núm. 3., (2019)

Esther Mónica Jara Fernández; Francisco Luis León Chérrez; Gabriel Yovany

Suqui Romero

pág. 14). Estas tres causas de exclusión encierran tras su mención un amplio abanico de posibilidades excluyentes de conducta entre las que podrían contarse ciertos trastornos de personalidad como las fobias, los actos de inhibición de la voluntad que pueden generar sustancias que de forma forzada o inconscientes se suministran al sujeto activo, por ejemplo. De ahí que, en este campo, jugará un rol determinante la actividad pericial.

La conducta, además de presentarse como acción, puede presentarse también como omisión. El precitado art. 23 ya trata parte de la omisión al establecer que "no impedir un acontecimiento, cuando se tiene la obligación jurídica de impedirlo, equivale a ocasionarlo" (Ediciones Legales, 2018), La omisión puede ser propia o impropia. La primera reflejada de forma expresa en determinados tipos penales como la omisión de control del lavado de activos, por ejemplo. La segunda, es abordada en el art. 28, donde detalla que omisión dolosa es la “obligación legal o contractual de cuidado o custodia de la vida, salud, libertad e integridad personal del titular del bien jurídico" (Ediciones Legales, 2018) y que sin embargo "ha provocado o incrementado precedentemente un riesgo que resulte determinante en la afectación de un bien jurídico” (Ediciones Legales, 2018).

Más allá de lo expresado, cabe destacar que el ordenamiento jurídico ecuatoriano siempre ha visto a la omisión como la inacción pura y simple, el no hacer, concibiéndose por tanto una visión psíquica de la omisión (García Falconí, 2014, pág. 249), aunque cabe recordar que la voluntad debe estar presente siempre en la omisión, voluntad que termina por dañar un bien jurídico (Albán Gómez, 2011, pág. 141). 


\section{La teoría de la imputación en la discusión doctrinaria actual. Especial referencia al Código Orgánico Integral Penal}

Vol. 3, núm. 3., (2019)

Esther Mónica Jara Fernández; Francisco Luis León Chérrez; Gabriel Yovany

Suqui Romero

\section{I.2.2. Tipicidad.}

Conforme al art. 25 del COIP los tipos penales describen los elementos de las conductas penalmente relevantes. La citada alusión recoge en cierta medida postulados de la doctrina finalista en el sentido que implica "la descripción objetiva, material, de la conducta prohibida" (Welzel, 1964, pág. 44), y refuerza la idea del principio de legalidad en la medida que "no puede haber delito sin tipo" (García Falconí, 2014, pág. 258).

Conocido es que esa tipicidad debe ser valorada tanto en sede objetiva cuanto en subjetiva, siendo en su primera dimensión en la que se deberá valorar los elementos estructurales objetivos que componen al tipo penal, como sujetos activo y pasivo, bien jurídico, conductas (acción, omisión propia e impropia) verbo rector, elementos normativos y descriptivos, entre otros. Es en esta sede de la tipicidad donde, a la luz del finalismo y funcionalismo, cobra relevancia la teoría de la imputación objetiva, ya que permite analizar la conducta del sujeto activo en estricta relación con el tipo penal por el cual se le acusa, dicho con otras palabras, permite determinar los cursos causales que tienen relevancia penal de los que no la tienen, para efectos de explicar el resultado final de la causa basal.

Actualmente a raíz de las reformas al COIP de 2019, se ha introducido de forma expresa el error te tipo que conforme al art. 7 de la Ley Orgánica Reformatoria al Código Orgánico Integral Penal lo introduce en el art. 28.1 del COIP con el siguiente texto:

"Error de tipo. No existe infracción penal cuando, por error o ignorancia invencibles debidamente comprobados, se desconocen uno o varios de los elementos objetivos del tipo penal. 


\section{La teoría de la imputación en la discusión doctrinaria actual. Especial referencia al Código Orgánico Integral Penal}

Vol. 3, núm. 3., (2019)

Esther Mónica Jara Fernández; Francisco Luis León Chérrez; Gabriel Yovany

Suqui Romero

Si el error es vencible, la infracción persiste y responde por la modalidad culposa del tipo penal, si aquella existe.

El error invencible que recae sobre una circunstancia agravante o sobre un hecho que califique la infracción, impide la apreciación de esta por parte de las juezas y jueces.”

En tanto que el error de prohibición lo ha direccionado en sede de la culpabilidad que no es materia de abordaje en este trabajo.

\section{I.2.2.1. Tipicidad Objetiva}

La adecuación de una conducta como por ejemplo, matar o robar, debe ser constatada con el catálogo de delitos presentes dentro del cuerpo normativo respectivo que en el caso ecuatoriano es el COIP. Si de la revisión de la conducta se da esa advertida constatación, es decir, la conexión entre el actuar de una persona con lo descrito en el tipo penal, se dice que la conducta es objetivamente típica. Para constatar tal conducta, es necesaria la correlación de la misma con "elementos referentes al autor, elementos referentes a la acción, al bien jurídico, elementos descriptivos y normativos, la causalidad”. (Bramont-Arias, 1996, pág. 194). En definitiva, de lo que se trata, es "de enjuiciar (valorar) si la conducta en cuestión pertenece o no al género de conductas que el legislador pretendía prevenir mediante esa norma” (UNAV, 2019)

La tipicidad objetiva encara a la vieja doctrina penal del positivismo naturalista, dejando de lado la valoración causalista para implantar criterios valorativos a las conductas que se les quiere dotar de relevancia penal. Esta valoración en criterios diferentes a la causalidad empírica igual no deslinda que ésta última sea un hito necesario para el entendimiento de la conducta 


\section{La teoría de la imputación en la discusión doctrinaria actual. Especial referencia al Código Orgánico Integral Penal}

Vol. 3, núm. 3., (2019)

Esther Mónica Jara Fernández; Francisco Luis León Chérrez; Gabriel Yovany

Suqui Romero

humana. Se entiende por tanto que una conducta será típica cuando "despliegue un riesgo suficientemente relevante desde el punto de vista del tipo en cuestión (tipos de mera actividad y tentativas), que se realiza en el resultado (en tipos de resultado)" (UNAV, 2019). Los aludidos recaudos doctrinarios, permiten la asunción al caso ecuatoriano, precisamente, de la necesidad de imputar objetivamente la conducta penalmente relevante conforme lo advierte el propio art. 22, que evidencia la necesidad dogmática de asumir que "el derecho penal es un derecho penal de acto y no de autor” (Muñoz Conde, 2018, pág. 7).

Recapitulizando, al hablar de imputación objetiva se estará ante la necesidad de verificar objetivamente todos los elementos estructurales del tipo, es decir, aquellos perceptibles a los sentidos.

\section{I.2.2.2. Tipicidad Subjetiva}

A diferencia de la anterior, la tipicidad subjetiva se erige como complemento de la objetiva y centra su atención en algo más allá del riesgo típicamente relevante, abarcando también en el conocimiento del sujeto activo, la subjetividad "con su potencialidad de conocer y querer" (UNAV, 2019)

Así como la importancia en la tipicidad objetiva radica en la necesidad de encuadrar la conducta "visible", o los elementos estructurales objetivos del tipo dentro de un tipo penal específico, en la tipicidad subjetiva esta importancia está presente en la exigencia de que el actuar penalmente relevante objetivo del sujeto activo, resulte doloso o imprudente. De ahí que 


\section{La teoría de la imputación en la discusión doctrinaria actual. Especial referencia al Código Orgánico Integral Penal}

Vol. 3, núm. 3., (2019)

Esther Mónica Jara Fernández; Francisco Luis León Chérrez; Gabriel Yovany

Suqui Romero

"en el sistema penal actual no es posible atribuir responsabilidad penal a una persona sin que exista una imputación subjetiva" (García Cavero, 2005).

Y es que, como se estableció al inicio de este subtema, la valoración tiene como objeto el $<<$ encuadre $>>$ de las conductas; en el punto de vista subjetivo, se debe analizar "la voluntad de acción del autor en tanto afectan la forma de realización del hecho, al objeto de la acción protegida por el tipo o al bien jurídico" (Bramont-Arias, 1996, pág. 194), ejemplo de esto se puede citar el tipo penal del femicidio, que en su efecto es idéntico al tipo penal de asesinato (dado que ambos lesionan al mismo bien jurídico: la vida). Así para ilustrar el presente caso, la muerte de la mujer por <<la condición de serlo>> o por sentimientos machistas al ser elementos normativos y descriptivos, en primera instancia, deberán ser acreditados en sede objetiva del tipo; luego el desprecio y la voluntad de matar bajo esas condiciones o sentimientos, serán elementos que se analizan dentro de la tipicidad subjetiva, ya que residen dentro de la psique del autor del delito.

\section{I.2.2.3. La Teoría de la Imputación Objetiva}

Habiéndose determinado que el análisis objetivo de la tipicidad se lleva a cabo al constatar la relación entre los elementos objetivos del tipo y la valoración subjetiva de la voluntad delictiva, es necesario precisar que la imputación "es la capacidad de entender y querer en el campo del derecho penal" (UAL, s/f), se trata del estadio de la teoría del delito más complejo de analizar, ya que se suman a los elementos objetivos del tipo penal la subjetividad del actor. Esta actividad que empieza en el COIP con la tipicidad del art. 25, se complementa con los arts. 26, 27 y 28. 


\section{La teoría de la imputación en la discusión doctrinaria actual. Especial referencia al Código Orgánico Integral Penal}

Vol. 3, núm. 3., (2019)

Esther Mónica Jara Fernández; Francisco Luis León Chérrez; Gabriel Yovany

Suqui Romero

Aunque ha sido tratada por varios autores, la teoría de la imputación objetiva en casi todos ellos encuentra sustento en los postulados de Roxin y Jakobs, que básicamente la estructuran o la analizan a la luz del principio de confianza, riesgo permitido, prohibición de regreso y competencia de la víctima.

\section{I.2.2.3.1. Principio de Confianza}

Es una relación en la que "cuando el que obra de modo conforme a Derecho en su ámbito de organización puede partir de que los demás también lo harán en el suyo, salvo que se haga evidente lo contrario" (Silva Sánchez, 2011, pág. 1).

El principio de confianza se desarrolla en dos niveles, que son dependientes de la relación que exista entre quienes interactúan. En las relaciones de carácter horizontal, "todos los interactuantes en un determinado contexto se encuentran en un mismo nivel, o bien, en niveles equivalentes" (Mayer Lux \& Vera Vega, 2018, pág. 335). Por su parte, "las relaciones verticales implican la existencia de distintos niveles o de un vínculo jerárquico entre quienes interactúan” (2018, pág. 335).

Precisamente es el principio de confianza uno de los elementos que deberán analizarse a la hora de imputar penalmente a una persona cuando por ejemplo, se presenta una infracción a la luz de una actuación bajo este principio. No se trata de evadir responsabilidad penal, sino de desechar del curso causal, aquellas conductas que aunque pueden llegar a ser penalmente relevantes, son ejecutadas en la confianza de que se está actuando como lo haría cualquier persona en una situación determinada. 


\section{La teoría de la imputación en la discusión doctrinaria actual. Especial referencia al Código Orgánico Integral Penal}

Vol. 3, núm. 3., (2019)

Esther Mónica Jara Fernández; Francisco Luis León Chérrez; Gabriel Yovany

Suqui Romero

\section{I.2.2.3.2 Riesgo permitido.}

Al estudiarse el riesgo permitido se valora el hecho de que existen ciertas actividades que por sus características propias entrañan un peligro en sí mismas, y “aún el correcto desempeño de esas tareas trae consigo un riesgo ínsito de acuerdo con la naturaleza y las particularidades cada una de ellas" (Cruz Ártico, 2015, pág. 6). En palabras de Jakobs, “cualquier contacto social entraña un riesgo, incluso cuando los intervinientes actúan de buena fe: a través de un apretón de manos puede transmitirse una infección, una anestesia aplicada de conformidad con la lex artis puede causar una lesión” (Jakobs, 2005, pág. 44). Lo que equivale a advertir que prácticamente vivimos en una sociedad de riesgos (Beck, 2004).

En las conductas humanas que pueden tener relevancia para el Derecho penal, identificar el riesgo permitido así como constatar su exceso, ayuda a determinar el grado de responsabilidad de una persona. Ejemplo de esto, es el anestesista que consciente de la complejidad de una intervención quirúrgica, no se cerciora de la cantidad de anestesia administrada a un paciente y le causa lesiones permanentes. Aquí el anestesista excede el riesgo permitido inherente a la práctica médica.

Un buen ejemplo para ilustrar este principio a la hora o no de una imputación penal objetiva, es el de aquel conductor (la actividad misma de conducción es un riesgo, pero permitido) que bajo efectos del alcohol conduce aunque de forma adecuada su vehículo. En este caso existe un exceso de riesgo permitido que se sanciona en el caso ecuatoriano como contravención por conducción en estado de embriaguez en el art. 385 del COIP. 


\section{La teoría de la imputación en la discusión doctrinaria actual. Especial referencia al Código Orgánico Integral Penal}

Vol. 3, núm. 3., (2019)

Esther Mónica Jara Fernández; Francisco Luis León Chérrez; Gabriel Yovany

Suqui Romero

\section{I.2.2.3.4 Competencia de la víctima (o autopuesta en peligro)}

De lo referido en el punto anterior, y en observación con los casos particulares que puedan darse, es necesario luego, revisar el grado de responsabilidad que tiene la víctima en estos sucesos, o lo que es igual "atribuir una relevancia decisiva a cómo se reparta la ejecución de la actividad arriesgada entre víctima y autor" (Barbirotto, 2011, pág. 6). Esto ya que “causar de modo previsible un resultado no significa necesariamente que ello también le incumba jurídicamente al causante" (Jakobs, 2004, pág. 36), sino que, en múltiples casos esta responsabilidad recae también en la víctima, que de manera consciente evalúa los riesgos que conlleva para su persona exponerse a cierta situación y aun así lo hace.

Siguiendo con el ejemplo planteado, en este caso aquél conductor que estado de embriaguez conduciendo de forma correcta es impactado por un motociclista que se cruza un semáforo en rojo provocándose la muerte. Lo que se nota en este ejemplo, es una clara contravención en los términos del citado art. 385. Luego la muerte del ciclista que se autopuso en peligro al cruzarse un semáforo en rojo, no le debe ser imputada al conductor conforme a la necesidad de competencia de la víctima a la luz de la analizada teoría de la imputación objetiva.

\subsubsection{Prohibición de Regreso}

La prohibición de regreso se erige como uno de los elementos más discutidos de la teoría de la imputación objetiva. En ese sentido, se afirma que autores como Rudolphi y Roxin discuten la posibilidad de su aplicación "con ayuda de deducciones llevadas a cabo a partir de conceptos abstractos y de pretendida validez general" (Parma, 2006, pág. 6). Este elemento de la 


\section{La teoría de la imputación en la discusión doctrinaria actual. Especial referencia al Código Orgánico Integral Penal}

Vol. 3, núm. 3., (2019)

Esther Mónica Jara Fernández; Francisco Luis León Chérrez; Gabriel Yovany

Suqui Romero

imputación objetiva hace referencia a los roles que cada ser humano ocupa en la sociedad.

Luego, juega un rol determinante el sistema de roles de Jakobs clasificados por determinado autor en especiales y comunes. Los primeros, son aquellos que se derivan de delitos de infracción del deber, donde prima una obligación institucional y en este sentido, puede citarse la obligación que poseen los padres en relación a sus hijos (Gutarra, 2019, pág. 1); los roles comunes por su parte, se enmarcan en la concepción de la vida en convivencia, donde no se vive solo, sino en compañía de los otros en un mismo mundo (Jakobs, 1997, pág. 73), entendiéndose además como el deber de no lesionar a los demás (Gutarra, 2019, pág. 2).

Si bien la prohibición de regreso, asoma en trabajos previos al de Jakobs, fue sin embargo éste, que le dio un giro, interpretando que no es "jurídico-socialmente congruente que el carácter delictivo de una actividad sea impuesto arbitraria y unilateralmente por el autor del hecho, aun cuando el posterior resultado lesivo producido se halle conectado causalmente con la aportación prestada por un tercero" (Jakobs, 2007, pág. 238).

\section{Conclusión.}

Del análisis sistemático y bibliográfico realizado, se puede colegir que el COIP no es solamente finalista, al contrario, se nutre de numerosas fuentes y consigo se crea un sistema que permite la apreciación de más de una corriente de la dogmática penal. Se advierte de igual manera la superación de los designios meramente causalistas que evidenciaba su antecesor, inclinándose por postulados finalistas cuando se denota la ubicación del dolo (Art. 26) así como de la culpa (art. 27) dentro de la tipicidad. De esta forma se verifica una coincidencia con el 


\section{La teoría de la imputación en la discusión doctrinaria actual. Especial referencia al Código Orgánico Integral Penal}

Vol. 3, núm. 3., (2019)

Esther Mónica Jara Fernández; Francisco Luis León Chérrez; Gabriel Yovany

Suqui Romero

pensamiento de Welzel, lo cual demuestra el acercamiento a los postulados finalistas de la acción.

Por su parte, postulados del funcionalismo a través de la teoría de la imputación objetiva son plenamente factibles con la propuesta regulatoria del COIP conforme se evidenció en este trabajo con el ejemplo del conductor analizado en alguna de las categorías de la citada teoría, de ahí que riesgo permitido, prohibición de regreso, competencia de la víctima y principio de confianza, son categorías que dependiendo de la inclinación dogmática de los operadores judiciales -finalistas o funcionalistas- tienen pleno asidero en el análisis de la teoría del delito ecuatoriana.

\section{Bibliografía.}

Albán Gómez, E. (2011). Manual de Derecho Penal ecuatoriano. Quito: Ediciones Legales.

Barbirotto, P. (08 de 2011). La imputación al ámbito de la responsabilidad de la víctima. Obtenido de Pensamiento Penal: http://www.pensamientopenal.com.ar/system/files/2011/08/doctrina30693.pdf

Beck, U. (2004). La Soeciedad del Riesgo. Obtenido de David Huerta Type Pad: https://davidhuerta.typepad.com/files/beck-ulrich-la-sociedad-del-riesgo-hacia-una-nuevamodernidad.pdf

Bramont-Arias, L. (1996). El Tipo Penal. Derecho y Sociedad, 188-194.

Cruz Ártico, J. (09 de 2015). El riesgo permitido en el Derecho Penal: fundamentos y determinación. Obtenido de Pensamiento Penal: http://www.pensamientopenal.com.ar/system/files/2015/09/doctrina42070.pdf

Díaz Aranda, E. (08 de 08 de 2018). Cuerpo del Delito ¿Causalismo o Finalismo? Recuperado el 22 de 05 de 2019, de Pensamiento Penal: http://www.pensamientopenal.com.ar/doctrina/46872-cuerpo-del-delito-causalismo-ofinalismo 


\section{La teoría de la imputación en la discusión doctrinaria actual. Especial referencia al Código Orgánico Integral Penal}

Vol. 3, núm. 3., (2019)

Esther Mónica Jara Fernández; Francisco Luis León Chérrez; Gabriel Yovany

Suqui Romero

Ediciones Legales. (2018). Código Orgánico Integral Penal. Quito: Ed. Legales.

Fernández Carrasquilla, J. (2011). Derecho Penal. Parte General. Bogotá: Ibáñez.

García Amado, J. (2000). ¿Dogmática Penal Sistémica? Sobre la influencia de Luhmann en la teoría penal. Recuperado el 22 de 05 de 2019, de Repositorio Institucional de la universidad de Alicante: https://rua.ua.es/dspace/bitstream/10045/10249/1/doxa23_09.pdf

García Cavero, P. (2005). La imputación subjetiva y el proceso penal. Obtenido de Dialnet Unirioja: https://dialnet.unirioja.es/descarga/articulo/5312302.pdf

García Falconí, R. (2014). Código Orgánico Integral Penal comentado - Tomo I. Lima: ARA Editores.

García Falconí, R. (09 de 06 de 2014). El Universo. Recuperado el 22 de 05 de 2019, de La teoría del error en el nuevo Código Penal: https://www.eluniverso.com/opinion/2014/06/09/nota/3079436/teoria-error-nuevo-codigopenal

Gómez Toledo, P. (2009). El delito de omisión impropia. Recuperado el 22 de 05 de 2019, de Repositorio Universidad de Chile: http://repositorio.uchile.cl/tesis/uchile/2009/degomez_p/pdfAmont/de-gomez_p.pdf

Gutarra, A. (2019). La Teoría de la Imputación Objetiva. Obtenido de Pensamiento Penal: pensamientopenal.com.ar/system/files/2019/01/doctrina47313.pdf

Iberley. (2013). Clases de teorías de la acción como primer elemento del delito: teoría causal, teoría final y teoría social. Recuperado el 22 de 05 de 2019, de Iberley: https://www.iberley.es/temas/teoria-accion-accion-primer-elemento-delito-47251

Jakobs, G. (1997). Derecho Penal Parte General. Madrid: Marcial Pons.

Jakobs, G. (2004). Sobre la normativización de la dogmática jurídico-penal. Bogotá: Universidad Externado de Colombia.

Jakobs, G. (2005). La Imputación Objetiva en el Derecho Penal. Buenos Aires: Ed. Ad Hoc.

Jakobs, G. (2007). La imputación jurídico-penal y las condiciones de vigencia de la norma. En C. Goméz-Jara Díez, Teoría de sistemas y Derecho penal. Fundamentos y posibilidad de aplicación (págs. 203-223). Lima : Ara Editores.

Larrauri Pijoan, E. (8 de 11 de 2016). Introducción a la Imputación Objetiva. Recuperado el 22 de 05 de 2019, de Ciencias Penales: http://www.cienciaspenales.net/files/2016/11/8_introduccion-a-la-imputacion-objetiva.pdf 


\section{La teoría de la imputación en la discusión doctrinaria actual. Especial referencia al Código Orgánico Integral Penal}

Vol. 3, núm. 3., (2019)

Esther Mónica Jara Fernández; Francisco Luis León Chérrez; Gabriel Yovany

Suqui Romero

Luzón Peña, D.-M. (2016). Derecho Penal - Parte General. Buenos Aires: B de F.

Maurach, R. (1994). Derecho Penal - Parte General I. Buenos Aires: Astrea.

Mayer Lux, L., \& Vera Vega, J. (2018). Autorización de plantas de revisión técnica e imputación objetiva en delitos culposos del tráfico vehicular. Revista de Derecho Validivia, 327-345.

Moya Molina, A. (2014). El Error de Tipo en la legislación ecuatoriana. Obtenido de Dspace UDLA: http://dspace.udla.edu.ec/bitstream/33000/2033/1/UDLA-EC-TAB-2014-77.pdf

Muñoz Conde , F., \& García Arán, M. (2004). Derecho Penal. Parte General (6ta ed.). Valencia: Tirant Lo Blanch.

Muñoz Conde, F. (2018). Teoría General del Delito. Bogotá: Temis.

Parma, C. (2006). La prohibición de regreso en el pensamiento de Jakobs. Obtenido de Revista Jurídica Online: https://www.revistajuridicaonline.com/wpcontent/uploads/2006/10/19_La\%20Prohibicion\%20de\%20regreso.pdf

Peña Gonzales, O., \& Almanza Altamirano, F. (02 de 2010). Teoría del Delito - Manual práctico para su aplicación en la teoría del caso. Recuperado el 22 de 05 de 2019, de Pensamiento Penal: http://www.pensamientopenal.com.ar/system/files/2017/11/doctrina46022.pdf

Roxin, K. (2014). Derecho Penal, parte general. Madrid: Marcial Pons.

Serrano, K. (2015). La exclusión de la voluntad en la conducta punible a consecuencia de los movimientos reflejos debidamente comprobados. Obtenido de Repositorio Utmachala: http://repositorio.utmachala.edu.ec/bitstream/48000/3491/1/CD00061-

TRABAJO\%20COMPLETO.pdf

Silva Sánchez, J. (2011). Deberes de los miembros de un Consejo de Administración [a propósito de la STS núm. 234/2010 (Sala de lo Penal), de 11 de marzo]. InDret, 1-5.

UAL. (s/f). Imputabilidad y su aspecto negativo. Obtenido de UAL - Universidad de Almería: http://ual.dyndns.org/biblioteca/Derecho_Penal/Pdf/Unidad_8.pdf

UNAV. (2019). 3 - El tipo doloso de comisión (II - La imputación subjetiva). Obtenido de UNAV - Universidad de Navarra: https://www.unav.es/penal/delictum/leccion3.html

UNAV. (2019). Lección 2da - El tipo doloso de comisión (I: La imputación objetiva). Obtenido de UNAV - Universidad de Navarra: https://www.unav.es/penal/delictum/leccion2.html

Vaca , R. (2014). Derecho Procesal Penal Ecuatoriano - Tomo 1. Quito : Ediciones Legales. 


\section{La teoría de la imputación en la discusión doctrinaria actual. Especial referencia al Código Orgánico Integral Penal}

Vol. 3, núm. 3., (2019)

Esther Mónica Jara Fernández; Francisco Luis León Chérrez; Gabriel Yovany

Suqui Romero

Velepucha Ríos, M. (2018). Error de prohibición. Recuperado el 22 de 05 de 2019, de Derecho Ecuador: https://www.derechoecuador.com/error-de-prohibicion\#_ftn10

Welzel, H. (1964). El Nuevo Sistema de Derecho Penal, (una introducción a la doctrina de la acción finalista). Barcelona: Ediciones Ariel.

Zaffaroni, E. (2007). Manual de Derecho Penal - Parte General. Buenos Aires: Ediar.

Zaffaroni, E., Alagia, A., \& Slokar, A. (2006). Manual de Derecho penal. Parte General (5ta ed.). Buenos Aires: EDIAR.

Zambrano Pasquel, A. (2017). Derecho Penal - Parte General. Quito: Murillo Editores. 